\title{
Preparations of Pomegranate By-Products are Effective as Dermatological Healing Herbal Medicine
}

\author{
Thelma B Machado*1,2,3, Felipe FM VIEIRA ${ }^{2}$, Keila CFA Silva ${ }^{1}$, and Maria Beatriz PP Oliveira ${ }^{3}$ \\ ${ }^{1}$ PPGCAPS, Faculty of Pharmacy, Federal Fluminense University, Brazil \\ ${ }^{2}$ Faculty of Pharmacy, Federal Fluminense University, Brazil
}

${ }^{3}$ Department of Chemical Sciences, Porto University, Portugal

Received: 制 January 16, 2019; Published: 䟧 January 25, 2019

*Corresponding author: Thelma de Barros Machado, Department of Pharmaceutical Technology , Faculty of Pharmacy, Federal Fluminense University, Brazil

\section{Opinion}

The use of phytotherapy and crude medicinal plants has great relevance worldwide and especially in developing countries, since it has a direct impact on health practices. Currently, in Brazil, the National Policy of Medicinal Plants and Phytomedicines (PNPMF) and the National Policy of Integrative and Complementary Practices (PNPIC) coordinate what is related to this subject in the country and, traditionally, most crops have been focused on obtaining a single high-value product, discarding the remaining parts of the plant or fruit, or exploiting them to obtain low value products [1]. Many of these materials are rich in polyphenols, which are capable of chemically binding to proteins, promoting their precipitation. This key behaviour is the basis for this class of substances to have a pronounced activity in treating wounds of difficult treatment [2]. The high incidence and consequent epidemiological recurrence of chronic wounds leads to an increase in researches aimed at identifying new therapeutic strategies for the treatment and prevention of these diseases. Researches in the area of natural products, especially the use of medicinal plants for this purpose, represents an important strategy to increase the therapeutic arsenal available for dermatological use.

Punica granatum L. belongs to the Punicaceae family and is a small tree native to the Mediterranean region. Its fruits, commonly known as pomegranate, have been known as a reservoir of bioactive compounds, especially polyphenols, with potential and important biological activities [3]. Pomegranate fruits are important sources of hydrolysable tannins, ellagitannins and ellagic acid [4]. They are also used as functional food ingredients in various forms, such as juice, jelly, and alcoholic beverages produced with fresh seeds, as well as spices prepared from dried seeds [5]. The pharmacological activities described in the scientific literature for the secondary metabolites isolated and identified from pomegranate fruits allow to relate to them a large number of therapeutic applications both for the prevention and treatment of dermatological diseases in which acute or chronic inflammatory process is involved. Following the premise that agrifood by-products are not residues but raw materials for new products and as part of our effort to identify the responsible substances for the pharmacological activities attributed to plants utilized in traditional medicine, we have studied the pericarp (peel) of pomegranate fruits in order to identify the components with antimicrobial activity [6].

In this study we have identified the ellagitannin punicalagin as the biological marker of pomegranate peel extracts, which were active against multi-resistant bacterial strains. Despite of the several studies involving the fruits of pomegranate, its active components and its possible applications as ingredients in products for the treatment of several diseases, there are not many works aimed at the standardization and stability evaluation of both extracts and products made from these materials. In this sense, our research group has been concentrating efforts to establish a biomarker and, consequently, the parameters of quality for the extracts made from pomegranate peels in an attempt to establish reproducible parameters for the qualitative standardization. In order to meet this objective, we proposed the formulation of a hydrogel based on extracts of pomegranate peels and evaluation of their physicochemical properties as well as their stability, having as a qualitative and quantitative parameter the content of the ellagitannin punicalagin $[7,8]$. We also have carried out a preparation of crude extracts of Punica granatum peels and from this the antimicrobial potential of a $2 \%$ aqueous solution was evaluated through a suspension test. An ethanolic solution of same concentration was used to prepare a healing hydrogel that has its microbiological quality control evaluated. 
The suspension test recommended by the Association of Official Analytical Chemists (AOAC) showed that after 5 and 10 minutes the aqueous solution did not promote death of the bacterial population, however after 15 minutes and 24 hours the reduction of the initial bacterial population was of 3 and 4 cycles of log, respectively. The microbiological quality control of the hydrogel showed that there was no growth of bacteria, including pathogens, during the test period ( 6 months). In our previous work we have showed that a hydrophilic base formulation made with extracts of pomegranate peel remains stable for three months of storage, showing no significant differences in the content of punicalagin when the product is stored in a temperature chamber or in a climatic chamber, which has more drastic storage conditions. The biomarker punicalagin, therefore, has a great stability [8]. In the daily care treatment of wounds there is a great concern with the process of hygiene of the lesions and with the products applied in them. It is usually a painful process for the patient, which increases the attention in the development of formulations with characteristics that make the hygiene easier to accept by the patient, reducing the discomfort and ensuring the periodic examination of the injured region [9].

Our results demonstrated that a hydrophilic based formulation made with standard extracts of pomegranate peels guarantees optimal dispersibility as well as adequate color, uniformity and odor. The results of the microbiological analyses demonstrated the stability of the product during the study period, showing efficiency of the production process and the components used in the formulation. Punicalin and punicalagin are the major secondary metabolites of the active extracts of pomegranate peels. Punicalagin when evaluated separately for its antimicrobial activity against multiresistant hospital staphylococcal strains demonstrated that this substance is responsible for the growth inhibitory activity, presenting a MIC of $62.5 \mu \mathrm{g} / \mathrm{mL}$ [6]. The hydrophilic-baseformulation containing a $2 \%(\mathrm{w} / \mathrm{w})$ ethanolic extract of pomegranate peels had a mean punicalagin content of $0.017 \%$. Under more drastic storage conditions (climatic chamber, $40^{\circ} \mathrm{C} / 75 \% \mathrm{RH}$ ), punicalagin content reached $0.011 \%$. In our previous studies it was observed that a $2 \%(\mathrm{w} / \mathrm{w})$ formulation would meet the requirements for a more stable product regarding the content of punicalagin, since the same product formulated with $1 \%(\mathrm{w} / \mathrm{w})$ presented the same MIC $(62.5 \mu \mathrm{g} / \mathrm{mL})$ of a silver sulfadiazine cream. The latter is used as a reference treatment in cases of burns and difficult-to-treat wounds with $1 \%(\mathrm{w} / \mathrm{w})$ formulations [10].

Toxicological and clinical studies, as well as long-term physical and chemical studies, are the subsequent steps to guarantee the quality and efficiency of products formulated with P. granatum extracts. For the extraction optimization of ellagitannins, we have used extractions assisted by microwave, which furnished higher content levels of this substances in comparison with static extraction techniques. All physicochemical studies of the P. granatum peel extracts and formulations were performed by an efficient HPLC-DAD method capable of distinguishing the biological marker punicalagin in a single run of $8 \mathrm{~min}$. The extracts of $\mathrm{P}$. granatum peels were then used to produce a topical phytomedicine formulation prescribed for the treatment of infected chronic vascular ulcers of a patient who was not responsive to conventional treatment with antimicrobials and corticosteroids for, at least, one year [8]. the results obtained in this study demonstrated the efficacy of the product in the treatment of chronic wounds, with complete closure of the wound after three months of treatment. The formulation presented an excellent physicochemical and sensorial performance. Punicalagin presented high stability, not being significantly affected by storage. Preparations of pomegranate byproducts are effective as dermatological healing herbal medicines and formulations containing extracts standardized at $0.049 \%$ $(\mathrm{w} / \mathrm{w})$ of punicalagin may be used for the treatment of acute and chronic conditions.

\section{References}

1. Peralbo Molina A, Castro MDL (2013) Potential of residues from the Mediterranean agriculture and agrifood industry. Trends Food Sci Tech 32(1): 16-24.

2. Murthy KNC, Reddy VK, Veigas JM, Murthy UD (2004) Study on wound healing activity of Punica granatum peel. J Med Food 7(2): 256-259.

3. Bekir J, Mars M, Souchard JP, Bouajila J (2013) Assessment of antioxidant, anti-inflammatory, anti-cholinesterase and cytotoxic activities of pomegranate (Punica granatum) leaves. J Food Chem Toxicol 55: 470475 .

4. Singh K, Jaggi AS, Singh N (2009) Exploring the ameliorative potential of Punica granatum in dextran sulfate sodium induced ulcerative colitis in mice. Phytother Res 23(11): 1565-1574.

5. Sheng W, Tian L (2017) Diverse Phytochemicals and Bioactivities in the Ancient Fruit and Modern Functional Food Pomegranate (Punica granatum). Molecules 22(10): E1606.

6. MachadoTB, Ivana CR Leala, Ana Claudia F Amaralb, Kátia RN dos Santosc, Marlei G da Silvac, et al. (2002) Antimicrobial Ellagitannin of Punica granatum Fruits. J Braz Chem Soc 13(5): 606-610.

7. The International Conference on Harmonisation ICH Q1A (R2) Available online: (accessed on 16 September 2018).

8. Fleck A, Cabral PF, Vieira FF, Pinheiro DA, Pereira CR, et al. (2016) Punica granatum L. Hydrogel for Wound Care Treatment: From Case Study to Phytomedicine Standardization. Molecules 21(8): E1059.

9. Staubach P, Metz MJ (2013) Magistral formulations and pruritus therapy - What is established, what is confirmed, what is new? Dtsch Dermatol Ges 11(11): 1049-1055.

10. Machado TB (2003) Análise fitoquímica e investigação da atividade antibacteriana de plantas medicinais utilizadas popularmente contra infecções. PhD Thesis, Universidade Federal do Rio de Janeiro, Rio de Janeiro, Brazil. 
ISSN: 2574-1241

DOI: 10.26717/BJSTR.2019.13.002425

Thelma de Barros Machado. Biomed J Sci \& Tech Res

(c) (i) This work is licensed under Creative

Submission Link: https://biomedres.us/submit-manuscript.php

$\begin{array}{ll}\text { BIOMEDICAL } & \text { Assets of Publishing with us } \\ \text { RESEARCHES } & \text { Global archiving of articles } \\ & \text { - Immediate, unrestricted online access } \\ \end{array}$

